\title{
Education, Cultural Change, Territory: The Third Sector' Innovation. An Italian Case Study*
}

\author{
Gaia Peruzzia, Raffaele Lombardia
}

\begin{abstract}
This contribution proposes a theoretical-empirical reflection on the relationship among the three sociological concepts identified by the authors as essential dimensions of the innovation: cultural change, education, and territory. The aim is to illustrate the complex relationship among these dimensions and the implications involved in terms of sociological perspectives and research tools, on the basis of the analysis of an emblematic case study: "FQTS", Italian acronym of the project of Education of Executives and Leaders of the Third Sector in the Southern Italy. In particular, this investigation will be aimed at: (re)defining sociological concepts considered fundamental for the study of innovation; reconstructing the main empirical evidence emerging from the analysis of the case study; and summarizing the relevance of the research results, in terms of new themes and sociological perspectives, as well as of methodological questions.
\end{abstract}

\section{Keywords}

Cultural processes, innovation, education, territory, third sector

Over the last two decades, the concept of social innovation has become very popular, not only in the literature of various scientific disciplines (social and political sciences, geography, and economics), but also in the policy and governance of territories, through the numerous projects and experiences inspired by this model. However, as is often the case when words enjoy such sudden fame, the term seems to have lost part of its semantic power, due to the multitude of uses and meanings that have been attributed to it.

What to date still seems difficult to fathom, yet ought instead to be a strategic component, is its link with one element in particular, namely the territory ${ }^{1}$. On one hand, it is not always easy to understand from the narratives of experiments carried out in different local contexts (alas, relatively few on the part of the social sciences), exactly what social innovation actually means for those territories involved. On the other hand, the inevitable role of the knowledge economy in these processes, which rely ever more on the opportunities offered by new communication technologies (in particular e-learning), in many cases portrays a de-territorialized image of the phenomena of social innovation.

This paper intends to get to the very heart of the matter, by investigating the deep relationship between the main concepts which are normally involved in any sociological discussion on this topic: What exactly is the relationship between social innovation and territory? Which are the social actors that can promote innovative cultures and practices in difficult or resistant contexts? And, specifically, which is the

\footnotetext{
${ }^{a}$ University of Rome "La Sapienza”, Italy

Correspondent Author:

Gaia Peruzzi, via Salaria 113, Rome, 00198, Italy
} 
factor that links education, organizations, and cultural change, that is, those elements indispensable to social innovation? Furthermore, how does social innovation manifest itself in a territory, in the daily life of the organizations and the inhabitants? What is the concrete impact of an increase in social capital and networks? Put another way, how is social innovation territorialized?

The answers to these questions are dealt with by the two authors through an empirical-theoretical analysis, which revolves around a case study that is considered in many respects to be exemplary of the very dimensions under investigation.

\section{THE THEORETICAL SCENARIO AND EXPLORATORY QUESTIONS}

Many sociological concepts crowd the linguistic field of social studies on innovation, but often they are used in a general and confused manner, without a proper explanation of their meaning and functions in reference to this theme.

This section is dedicated to an overview of the sociological concepts recurring in the scientific discussions on social innovation. It aims to focus on the distinctive features that a sociological perspective is able to shed light on in the analysis of a project or a practical experience. Albeit inevitably succinct, the reconstruction of the definitions of the concepts will be supported by a critical review of the international literature. The starting point will be the analytical examination of the expression social innovation; followed by an attempt to delve deep into the links and contradictions between the concepts under examination, as well as the discrepancies between the symbolic and the concrete levels of action they imply.

Although manifold, the various definitions of social innovation all converge around a group of elements that represent an "essential" core meaning. Hence, social innovation is considered to be those ideas, services, processes, and products that are designed to satisfy social needs, and that establish the creation of new relationships and new networks (Boccacin 2009; 2014).

Specifically, we define social innovations as new ideas (products, services and models) that simultaneously meet social needs (more effectively than alternatives) and create new social relationships or collaborations. In other words they are innovations that are both good for society and enhance society's capacity to act. (Mulgan and Pulford 2010: 18)

Social innovation is, therefore, a form of change that is attentive to the needs and to the more relational—indeed, social—dimension of society.

It is precisely this social vocation, mindful of the requirements of the community and aspiring to a widespread dissemination of new mentalities and new practices, which distinguishes our innovation, giving it both an ethical dimension and orientation. This is in stark contrast to the innovative projects realized in the world of business where any advantages are primarily, or even entirely, to the benefit of the owners.

Indeed, although in practice there have been a multitude of ambiguous cases, with participation from a variety of sources, the primary and indeed ideal promoters of social innovation experiences are the public bodies and civil society. That is to say, all those bodies (non-profit organizations, human rights movements, and active citizens) are acting in the name of the common good (Calise and Lowi 2010; Peruzzi 2011; Peruzzi and Volterrani 2016).

However, social justice, solidarity and sustainability are, according to a review of the literature, the inspirational principles behind all these strategies for change.

Although the fields of application for social innovation are potentially infinite, the following preferred areas of intervention have been operationally identified: social enterprise, technology, design, public policies, urban development and community policies, social rights, and social movements (Mulgan 
et al. 2007: 6). These same areas have also been identified in the context of policy and investment planning (in the last decade, social innovation has been one of the recurring themes in local and international bids for development proposals).

It is more difficult to narrow down the methods and tools through which social innovation is created and spread. This is because these depend on the particular scope in question, as well as on the contingent situation, and also because, in many cases, the innovation consists precisely of the original nature of the very processes that are being activated. However, a minimum common denominator can be found here too, consisting of the following factors: promoting the empowerment, both of the categories targeted for the intervention and more generally of the active members of the territory; the use and dissemination of good practices, as well as of "positive" deviant practices; and the creation and consolidation of network infrastructures. In confirmation of this, all three of these factors have been found to be cited as either the elements of a process or, alternatively, as the products of an innovation.

From a sociological point of view, one of the most interesting aspects regarding the diffusion of this culture of social innovation is undoubtedly the newfound centrality of education, something which entire local communities have to measure up to. Something bordering on a knowledge revolution has grown from this situation. What started off as scientific has also become social, thanks to the need for interrelations between knowledge-producing organizations (universities, research centers, and training agencies) and social actors (Kirat and Lung 1999).

Some authors also underline that an ability to activate and to coordinate local resources, as well as resources from outside investors, is a crucial factor for stimulating innovation.

Let us now pass on to another very important concept under analysis. In the social sciences literature more generally, as well as in the more specific social innovation literature, territory is a social construct, or to be more precise, a portion of space that implies the action of a social actor: an individual, or more often, as in this case, a community. To talk about territory (and territorial development) means acquiring a situational awareness, attentive to spatial and temporal dimensions. This is because the territory is a local context, as opposed to national, yet inevitably related to the global context. Furthermore, to consider a territory means to adopt a bottom-up perspective, the point of view of the local community: indeed, a territory is constituted precisely by the needs, actions, and relationships of its inhabitants (Angeon 2008; Colletis-Wahl, Peyrache-Gadeau, and Serrate 2008; Crevoisier et al. 2008; Fournis 2012; Van Dyck and Van den Broeck 2013).

The territory thus conceived is both a field of action and a variable for analysis. The territory taken as a space, as a contingent location, is the whole which comprises both the constraints and the opportunities that either hinder or favour social innovation. The territory as a variable is the awareness that the products of social innovation will change according to the territory of reference, and that the latter will always have an impact.

The territory works as an intermediary agent in the relationship between social actors and the environment, also creating social bonds. It is a space that is circumscribed, shaped, and occupied by a community, which is at the same time both a tool and a setting for its reproduction, acting as a creator of social ties among inhabitants. The community manages, plans, regulates and lives the territory. But, in this manner-managed, planned, regulated and lived-the territory itself establishes differentiated perceptions and inclinations within the inhabitants, influencing their relationships. (Klein 2008: 42; translated by the authors from the original French language)

So what exactly is the relationship between social innovation and territory? In the opinion of both the present authors, it is rooted in the very definition of 
social innovation. If, as mentioned above, and as all authors agree to recognize, our innovation is social because it responds to social needs, then it is in fact linked to the territory: social needs are not conceivable without reference to a particular community, and to a context located in a defined time and space. Therefore, the local setting, understood as an expression of needs and as a collection of potential resources, is, or at least should be, the very reason for, and the driving force behind, experiments promoting change and collective regeneration.

The local setting, considered in all its forms - that is, as a region, an agglomeration, an urban quarter or district-is the base from which it is possible to set up initiatives and projects of economic development that activate civil society. (Klein 2008: 47-48)

Over time, however, the equilibrium of this triangulation (social innovation-territory-local community) has been undermined by a new factor. As Kirat and Lung (1999: 27) pointed out some years ago: "The relationship between innovation and territory actually pertains to the interactions between learning processes, their institutional contexts and space". Nowadays, in almost all social innovation experiences, a central role is played by the processes of education and empowerment. The dissemination of new technologies and network infrastructures, on one hand, has considerably expanded the opportunities and modalities of new training schemes (e-learning courses, online collaboration platforms, and distance partnerships). On the other hand, this has meant that the more traditional processes are becoming overshadowed, in some cases even projecting a de-territorialized image of social innovation, made up merely of immaterial and impersonal processes. Intuitively, such a shift in emphasis raises very important questions: if the importance of the territorial factor is waning, then it is the very notion of "social" which needs to be reviewed, along with all the possible related formal and ethical implications.
It is in the context of the above scenario that the present research has taken shape. The aim is to investigate the territorial dimension of social innovation in its numerous forms via the examination of an empirical case study.

\section{THE CASE STUDY}

The chosen case study is considered emblematic, precisely in terms of the plurality of sociological perspectives that it enables researchers to explore. In fact, it is characterized by meaningful features concerning all those dimensions identified as the milestones of social innovation: territory, cultural change, and education.

Firstly, the project involves a very complicated territory, Southern Italy, which sadly is renowned at international level as an example of resistance to innovation; secondly, the "high level" objective of the project is the revival of this context by provoking a deep cultural change in the mentality and practices of its inhabitants; finally, innovation is sought through a considerable investment in education, via a complex system of blended learning, which occurs simultaneously in both online and offline territories.

The case under scrutiny is FQTS ${ }^{2}$ : this is a training course for the leading executives and managers of the Third Sector in the South of Italy. The objective is to initiate and spread, throughout those territories involved, processes which foster a culture of freedom, peace, and solidarity.

This project is a true social innovation experiment, proposing intervention in a territory that, as mentioned above, is both complicated and resistant to cultural change, namely Southern Italy. It adopts an innovative, "bottom-up" method, in other words, directly promoted by civil society, i.e., by organized associations, rather than by public institutions, as had previously been the case, for decades and with little success.

Formally, FQTS is a strategic line of intervention on the part of the "Fondazione con il Sud" 
(Foundation with the South), managed by the "Forum Nazionale del Terzo Settore" (National Forum of the Third Sector), in collaboration with the main Italian non-profit networks. The central role of the Third Sector in this project is another important element which influenced the selection of this particular case study: in fact, most analysis in international literature on social innovation concerns experiences promoted by enterprises and public institutions; and, above all, the Third Sector is one of the emergent social actors in Italian and European political life.

The data confirm the robustness of the project: two multiple-year editions, over almost 10 consecutive years; the constant involvement of six regions (Campania, Puglia, Basilicata, Calabria, Sicily, and Sardinia); 700 non-profit organizations activated; over 4,500 participants over the years, including tutors, operators, and collaborators; and a network of university partnerships that already involves more than 20 universities, both in Italy and abroad.

FQTS is a complex training mechanism, organized as follows: a general course regarding the identity issues for the Third Sector (Contemporaneity, Identity, Principles of Action, Internal Quality of an Organization, and External Relations), as well as four curricula dedicated specifically to various aspects of life in the South: Territory; Citizenship; Wellness; and Future. For each curriculum, there are a series of themes, dealt with in self-contained modules, and articulated across three didactic levels: general visions and policies, tools and action models, and experiences and practices in the field.

Participants are selected by the associations active in those regions involved; for each one, the team of trainers evaluates their attitudes, interests, prior training, and professional goals.

In operational terms, the project is based on an integrated system featuring face-to-face training sessions, alternated with a highly-structured distance learning programme; this comprises a special ad hoc e-learning platform, a virtual classroom which permits interaction between tutors and trainees in collaborative and peer-to-peer learning sessions. Finally, pilot groups and regional coordinators are responsible for the planning and organization of feedback sessions for opportunities of experience-sharing, as well as for the sharing of any knowledge, skills, and competences acquired regarding the territories.

\section{THE METHOD AND STAGES OF THE INVESTIGATION}

This case study was subjected to two levels of analysis, in an integrated approach, adopting both quantitative and qualitative research procedures and methods: on one hand, making use of materials previously produced by the scientific committee for the project, for the purposes of evaluation, monitoring, and planning; on the other hand, using original materials produced ad hoc specifically for this study. The first phase, in particular, required a huge effort in terms of the collection, analysis, and systematization of materials from over a nine-year time span. Indeed, the project, now enjoying its second multiple-year edition, is in its eighth year, and it is on this lengthy time span that the reports and all the collected documents are based, including: project forms; reports from training interventions; evaluation reports from intensive training weeks; annual reports; and customer satisfaction surveys.

Whereas, the original materials and those research actions directly designed by the authors focus on the latest edition (2015-2016) and, in particular, on the Future curriculum that, in the training project, is dedicated to cultural policies for the Third Sector.

What has proved crucial to this analysis has been the direct and indeed participatory observation, carried out over a long time span, throughout all stages of the project: from the conception to the design and final delivery of the training programme. The authors were able to attend organizational meetings as well as intensive training weeks, entering into direct contact 
with project managers and coordinators. This enabled them to gather the most important feedback regarding the impact the project has had on its participants over the last two years. Similarly, the observation and monitoring of relationships was also carried out for distance learning activities, through video conferences, online meetings, and participation in activities on the ad hoc platform, a virtual meeting place for the hundreds of participants.

The material listed, collected, and analyzed thus far has enabled the highlighting of a number of elements of great interest in the relationship between social innovation and territory, with particular reference to the concrete innovative practices that are attempting to respond to the social needs of the regions of Southern Italy. Research materials were used that had been produced for other purposes, primarily evaluation and monitoring reports, and which permitted a secondary analysis of the data already produced by the scientific committee of the project. Additionally, an independent path of research was followed, aimed at examining the concrete impact of social innovation on the territory, as well as the elements of resistance to change that characterize this geographic area. Indeed, what has played a crucial role in this challenge has been the opportunity to talk to privileged witnesses by means of a semi-structured interview $^{3}$, which is certainly the most original contribution of this work. This has enabled the gathering of comments, criticisms, and in particular concrete experiences, in the very words of the protagonists of this project (Montesperelli 2014: 255-265). The outline for the interview, in accordance with the general methodology guidelines, was constructed on the basis of a flexible and non-standardized framework (Corbetta 1999: 405). This was so as to allow a real "extended conversation" with the interlocutor (Amaturo 2012). The highly exploratory goal was to get as much detailed and in-depth information as possible on a variety of topics which had previously been identified and selected as the focus of the survey, thus gathering concrete examples based on the stimuli the authors had chosen to guide the conversation.

Something which proved to be central in this process was having direct access to the perspective of the interviewees, thus capturing their thoughts and their interpretations. Although there was a common interview framework, the direction each interview took was essentially dictated by two factors, one constitutive and the other circumstantial. On one hand, the differences between the participants in terms of role and responsibility within the project allowed the authors to foresee at least one specific thematic area to be addressed and adapted according to the particular competences of the interlocutors; on the other hand, being a semi-structured interview (hence the aim was not a standardized and closed sequence of questions and answers), each interview was characterized, above all, by the emphasis that the interlocutors chose to place on the proposed themes, developing those areas that spontaneously came up during the course of the interviews (Corbetta 1999: 423). The three main thematic areas in question are: the concrete implications of the project for the territory, identifying practices that are considered innovative compared to those previously adopted; the impact and reactions that the innovation has brought about in the territory, and which elements have favoured or hindered the cultural change; and the reaction to new practices of adult education, particularly online, and research activities. Finally, the last topic of conversation with one subgroup of privileged witnesses, namely project managers and coordinators, sought to develop reflection on the relationship between territory and social innovation, and not merely from the perspective of Southern Italy.

In all, nine interviews were conducted with: managers and coordinators both of the project itself as well as of those organizations promoting it; representatives of the regions involved; and those in charge of monitoring and evaluating the project ${ }^{4}$. The 
interviews were conducted between September and December 2016, and were all recorded and transcribed in full.

\section{WHEN THE THIRD SECTOR PRODUCES INNOVATION: A REVIEW OF THE POSSIBLE BENEFITS}

In light of an analysis of the documentation and of the interviews with privileged witnesses, the following two sections lay out the most important findings identified by the social innovation experiment. In this section, attention is focused on the positive impact the educational project has had on the territories involved, including the most frequent signs of change and innovation. In the following section, the main criticisms of the social innovation experience are outlined. In both cases, the evidence is such because it is looked at from the perspective of the territories (regions, organizations, and inhabitants) involved in the social innovation, bearing in mind also the relationship between physical territory and imaginary-virtual territory.

Among the most important concrete elements, mentioned by many interviewees, and therefore dealt with below, are: the increase in new networks, in terms of alliances, partnerships, and collaborations; the training, and therefore the renewal, of the professional-managerial class of the Third Sector in Southern Italy. A third element, transversal to the themes of networks and training is: the role that technology has had in this process of social innovation. Finally, for each theme identified, the elements of innovation, in terms of process and product, have been underlined.

The increase in relations, both interregional as well as with those even further afield, has been a concrete product of the innovation. It is first and foremost the result of a widely-shared need within the territory for "acknowledging one another and joining forces" and of an important and necessary cultural change: enhancing the image of the Third Sector. From the customer satisfaction surveys and from listening to interviewees, what clearly emerges is that the main element for innovation lies in the mutual acknowledgement of identity. This has triggered, among participants, the sense of belonging to a specific section of society as well as a way of interpreting and looking at reality. Working on identity and integrating the various perspectives, both that of the Third Sector and that of the specific territory of intervention, has created alliances, enabling comparison, from a collaborative point of view, with renewed technical, organizational, and planning skills. What proved crucial was the understanding that any effort in terms of planning may be futile without the creation of a meeting place for the comparison and exchange of experiences, for the recognition of those elements of commonality, as well as those, already widely recognized, of differentiation:

A place for the reciprocal exchange of content and experience between those in contact with the territory and those in contact with the institutions. There is a greater opportunity to "talk" with the various organizations, hence less conflict and competitiveness, generating a greater and more tangible capacity for collaborative planning. (Director of the National Forum of the Third Sector)

This improvement in planning skills is a beneficial consequence of the creation of a community. It is no coincidence that the last two years have been characterized by an increase in network participation in local calls for bids and proposals. This has given rise to new partnerships and alliances with a noticeable greater ability to tackle issues of collective interest and to create projects from original ideas. In this respect, the establishment of the Regional Forums has been a very welcome result and a sign of change which, for the South, should not be underestimated:

Innovation lies first and foremost in the creation of a large network which becomes formalized and institutionalized within the National Forum, giving voice to 
those territories that increasingly struggle to be heard. (Spokesperson for the Forum of the Third Sector Calabria)

The creation of new networks of relationships and partnerships, as became clear from the interviews, was also favoured by the territorial and organizational horizontality, resulting in an improvement in relations, in terms of trust and collaboration between the institutions and the organizations within the territory. It has proved a positive relational approach, less focused on the traditional position of "subjection" to the public institutions. Furthermore, in terms of "victimhood" and self-referentiality, it seems to have provided the key to unexpected partnerships and collaborations, particularly considering the heterogeneity of those working in the social sector:

There is a greater sense of pride. A sense of belonging that perhaps, culturally speaking, has always existed in the South. However, before there was more recrimination and complaining. These are feelings that have not disappeared, but they are now embedded in more knowledge and awareness, on one hand towards the problems which arise, and on the other towards people's own abilities and potential to make a difference in the territory. (Director of the National Forum of the Third Sector)

Overcoming the local boundaries of individual organizations was only made possible due to simultaneous work in both real and virtual meeting places. Also, and above all, considering the physical configuration of the territory in question. This is a territory heavily characterized by geographical areas where the distances are exacerbated by a mobility which is both problematic and costly, a lack of services and infrastructures, and a digital backwardness that undermines the potential for the employment of technology:

Moving from a physical connection to a virtual connection is an important innovation, not only for the project itself. It opens up a whole world of opportunities for the Third Sector and an added value for the Region in general: the creation of a cultural capital which can also be used in other contexts. (Spokesperson for the Forum of the Third Sector Puglia)

It is precisely such technology that brings us to the second point made at the beginning of this section: the training of a renewed professional-managerial class. Indeed, the considerable increase in the use of technology has enabled the acquisition of methods of learning and relating that, for the majority of participants, represent an absolute novelty and a tangible capital that can be invested directly in the territories. This effect, moreover, is evident from the huge sway towards digital communication that the programmes and ideas originating from the project have taken over the last two years. It is the sign of a significant product innovation.

Even in this case, however, innovation is not limited to the creation of previously inexistent products (tools, portals, and a community). As the President of the Fondazione con il Sud (Foundation with the South) reiterates, the objective is still the "creation of a professional-managerial class that is competent, renewed, reinforced and able to effectively replace the previous one". The aim is to directly address the roles and functions of management in the Third Sector to create a social capital that, both during and after the project, will be re-introduced into the organizations, representing a cultural model based on awareness and the importance of belonging to a group with common goals, both civic as well as in terms of solidarity.

It is no coincidence that the participants agree above all on one element from among the strengths: the innovative and original nature of the proposed themes, compared to the classical curricula of the non-profit education schemes. The innovation, in this sense, is not in the method but in the training programme. The long-established and highly structured training schemes in the Third Sector have been on the increase in recent years, focusing mainly on management and communication within 
organizations. In FQTS, training does not aim merely at innovating processes, but focuses on changing perspective, in the cultural sense. It does this by focusing on a programme that, in addition to being formative is also, in a certain sense, a path of learning for life, and touches on the most emergent areas of current social intervention:

It is about being able to create a group of people who, though coming from different experiential backgrounds, have learnt to share a process that is not only formative, professionally speaking, but also for life in the wider sense. In an anarchic world such as that of the Third Sector, it is perhaps the most important thing that could have been done. The work has concentrated on people, not on skills, and has led to the awareness that the aspects that unite us are greater than those which divide. (Spokesperson for the Forum of the Third Sector Sicily)

\section{THE OTHER ASPECT OF THE EXPERIMENTS IN SOCIAL INNOVATION: WHEN THE TERRITORY RESISTS CULTURAL CHANGE}

Are there any critical issues in the process of inducing social innovation by stimulating education, empowerment and new relationships in a difficult context? Can the territory also be a hindering or constraining factor for a project of innovation, and, if so, how does this resistance manifest itself? Examining even the "negative" side of the triangulation among non-profit organizations, education and territory seem particularly useful. Especially in view of the fact that, as has been noted in the literature (Moulaert et al. 2013), the popularity of the concept of social innovation seems primarily related to its incredibly widespread use on the part of non-profit organizations, think tanks, corporate management practices and, in particular, in government investment programmes destined to finance national and international development projects: all activities oriented towards the promotion of innovation, and therefore inevitably more likely to underline the potential for development, rather than the problematic aspects. On the other hand, for the purposes of a critical analysis, it is important also to consider the most ambiguous aspects of the relationship between social innovation and territory, sociologically interpreted, as explained above, as the relationships among its inhabitants, institutions, and organizations. The following are the factors that have emerged from an examination of the case study.

A difficult territory can present resistance to change. Southern Italy, as is well known, is an emblematic context of resistance to innovation. Despite possessing an enviable artistic and natural heritage, as well as a history interwoven with various cultures, for centuries it has been afflicted by extraordinary rates of poverty, unemployment, corruption, and crime. Living conditions and development prospects are compromised to the point of deserving the label and age-old category, known as the "questione meridionale" (Southern Issue).

In the specific case of the project in question, the resistance of the territory manifested itself above all in the form of resistance on the part of the organizations. As reported by more than one interviewee, the main obstacle when spreading new practices and energy throughout the six regions involved, is to be found in the diffident, even hostile reaction of members of associations who have not directly experienced the FQTS programme:

I fear that we have discovered an excellent fuel (the participants) but the car (i.e., the associations) is not in a position to exploit its potential, just as the roads (the institutions) are not adequate for the speed that such fuel might allow us to reach. (Spokesperson for the Forum of the Third Sector Sicily)

Another serious problem for the development of the project was found to be the difficulty of recruiting young people: since the management of Third Sector organizations are not professionals, it is obviously not easy to find people willing to invest, free of charge, 
the time and the energy required by a long and complex project like FQTS. The conciliation of the periods spent between life and work is an ongoing problem (Tremblay and Alberio 2013). However, interviewees pointed out that in this case, the variable "territory" is a highly relevant factor: lack of work and services, and an often "cold" relationship on the part of citizens towards institutions and trade unions-all chronic elements of the Southern Issue-were cited as obstacles to youth participation.

Finally, also worthy of a mention are the constraints and tensions that emerge from a cultural perspective in terms of the training processes. Namely in the design and delivery of the didactics, which, it must be pointed out, is the very cornerstone of this project. In this regard, two aspects, which are only apparently contradictory, were reported.

On one hand, in such an ambitious project, which aims to train a professional-managerial class, the territory demands that more attention should be paid to the specificities of each individual region: the label "South", just like the "Southern Issue", is considered too generic to account for the complexity of contexts that need to be analyzed, and understood, in-depth, taking account of all the specificities of at least six different areas.

On the other hand, it is also required that the territory should be overlooked, at least as a thematic anchor point for modules and activities, because:

In the end, what worked best were the proposals that forced the participants to make comparisons with something different... not exotic, just "different", with another feasible, achievable alternative. (Member of the Scientific Committee)

The power of such educational processes consists of opening up new worlds and perspectives to participants; the possibility that the expectations stimulated by the cultural paths go beyond the (physical and symbolic) boundaries imagined by the promoters of the project. Although this is undoubtedly an interesting outcome from a cultural perspective, it has to be taken into account that a "deviation" from the original goals can produce gaps between classes, as well as between the organizations and institutions promoting the project.

\section{CONCLUSIONS}

The theme of innovation has taken centre stage in research in the fields of both technology and organizational studies. However, the more specific aspects of social innovation have evidently received less attention, particularly when considered within the concrete perspective of a specific social actor (enterprise, public institution, or no-profit organization) as well as of a specific territory (Mulgan et al. 2007: 5). The primary aim of this paper was to investigate the potentiality of a sociological perspective, on an empirical-theoretical level, referring to an original and emblematic case study. Thus an attempt has been made to capture the visible and tangible elements of change, both on a physical and symbolic level, and to define and concretely link the sociological concepts, in order to test their capacity to describe and explain social phenomena.

At a more operative level, the goal of this paper was to investigate the role of the Third Sector, an emergent actor in the public sphere of many European countries, in producing cultural change.

The chosen setting was Southern Italy, a territory emblematic of the resistance to cultural change and social innovation.

Research has revealed the strategic role of systematic training programmes as a lever for change, and of social innovation and human capital as the main vehicle for social infrastructure development. Investment in the territory, through training courses, leads first and foremost to the creation of a cohesive, competent, and "online" human capital. This is achieved through the joint creation of projects, proposals, associative structures or representative 
bodies (e.g. Regional Forums), and the consequent participation in calls for bids and funding. Third Sector organizations are, even today, not free from forms of resistance and backward thinking regarding anything that represents innovation. They have become the protagonists of a process of change that attempts to overcome any obstacles in the precise moment when the territorial specificities are being evaluated, whilst maintaining the identity core that is common both to these experiences, as well as to the people who dedicate themselves to the social sphere.

Today's society is one in which the peculiar role of "educator" (Buccolo 2015: 9-14) emerges when all those involved in a territory join together, each with their own specificity, in the realization of projects of growth in which there is mutual empowerment (Tramma 2009). In this knowledge- and communication-based society, the two components of the territory, the physical and imaginary/imagined, are mutually interfering, forming a heuristically useful variable for understanding the needs of social innovation.

Finally, this case study has proved useful for the literature which very often is merely theoretical, or else micro-experiential, focusing on projects that are very specifically localized in time and space. Furthermore, it has contributed in terms of providing elements of consolidation for the now-numerous, yet often informal, Third Sector training schemes, as well as elements of comparison for the concrete prospects of training in terms of social innovation.

\section{Notes}

* This paper is founded on the results of a research that have been discussed by the authors in two international conferences: Italian Association Conference and University Federico II of Naples-Making Education through Culture. Making Culture through Education (Naples, October 13-15, 2016); 17th International Conference NTI, 4th International Conference and ICSR Mediterranean Knowledge-Collective Intelligence and Innovative Territories. Transitions, Cultural Changes and Inequalities
(Salerno, October 23-24, 2018). It is the joint work of two authors, for the purposes of an evaluation of the research and scientific quality of the work; the authorial responsibility may be attributed as follows: Gaia Peruzzi: sections 1, 2, and 5; Raffaele Lombardi: sections 3, 4, and 6; Abstract and Introduction have been written by both the authors.

1. Without entering into the details of the academic debate between the sociology of the territory and the sociology of the environment, and being conscious that a contraposition between culture and nature is senseless, in this paper the authors refer to the term territory, in order to underline the role of social actors (individuals, communities, institutions, and organizations) and their relations and cultures in constructing and changing the identity and image of the spaces we live in (Storey 2012).

2. FQTS is the Italiana cronym of "Formazione Quadri e dirigenti del Terzo Settore".

3. A framework was constructed based on the topics to be discussed during the interview. The questions were of a general nature and in no set sequence (Marradi 2005; 2012).

4. The following persons were interviewed, in this order: the president of the Fondazione con il Sud; the director of the Forum Nazionale del Terzo Settore; the head of educational programmes for the Forum Nazionale del Terzo Settore and national coordinator for the FQTS project; the spokesperson for the Forum Terzo Settore in Sicily; the spokesperson for the Forum Terzo Settore in Puglia; the spokesperson for the Forum Terzo Settore in Calabria; two supervisors for the evaluation and monitoring of FQTS; a member of the scientific committee for the project and coordinator for one of the learning curricula.

\section{References}

Amaturo, E. 2012. Metodologia della ricerca sociale (Methodology of Social Research). Torino: Utet Università.

Angeon, V. 2008. "L'explicitation du rôle des relations sociales dans les mécanismes de développement territorial" (Role of Social Relationships for the Comprehension of Territorial Development Mechanisms). Revue d'Économie Régionale \& Urbaine 2:237-250.

Boccacin, L. 2009. Terzo settore e partnership sociali: buone pratiche di welfare sussidiario (Third Sector and Social Partnerships: Best Practices of Subsidiary Welfare). Milano: Vita \& Pensiero.

_. 2014. "Italy's Third Sector Multilevel Organizations and Social Partnerships.” Italian Sociological Review 4(1):25-50.

Buccolo, M. 2015. "La comunità educante: quale educazione 
per il futuro" (The Educating Community. What Education for the Future)? Pp. 9-14 in Educazione, comunità $e$ politiche per il territorio (Education, Community and Policies for the Territory), edited by E. Napolitano. Milano: Franco Angeli.

Calise, M. and T. J. Lowi. 2010. Hyperpolitics: An Interactive Dictionary of Political Science Concepts. Chicago: University of Chicago Press.

Colletis-Wahl, K., V. Peyrache-Gadeau, and B. Serrate. 2008. "Introduction générale. Les dynamiques territoriales: quelles nouveautés" (General Introduction. Territorial Dynamics: What Is New)? Revue d'Économie Régionale \& Urbaine 2:147-157.

Corbetta, P. 1999. Metodologia e tecniche della ricerca sociale (Methodology and Techniques of Social Research). Bologna: Il Mulino.

Crevoisier, O., B. Pecqueur, V. Peyrache-Gadeau, and B. Serrate. 2008. "Conclusion: Dynamiques territoriales: quels chantiers de recherche" (Conclusion: Territorial Dynamics: What Research Projects)? Revue d'Économie Régionale \& Urbaine 2:265-268.

Fournis, Y. 2012. "Le développement territorial entre sociologie des territoires et science régionale: la voix $\mathrm{du}$ GRIDEQ" (Territorial Development Between Sociology of Territories and Regional Science: The Voice of GRIDEQ). Revue d'Économie Régionale \& Urbaine 4:533-554.

Kirat, T. and Y. Lung. 1999. "Innovation and Proximity: Territories as Loci of Collective Learning Processes." European Urban and Regional Studies 6(1):27-38.

Klein, J.-L. 2008. "Territoire et régulation: l'effet instituant de l'initiative locale" (Territory and Regulation: The Institutionalizing Effect of the Local Initiative). Cahiers de recherche sociologique 45:41-57.

Marradi, A. 2005. Raccontar storie (Telling Stories). Roma: Carocci.

—. 2012. Metodologia delle scienze sociali (Methodology of Social Sciences). Bologna: Il Mulino.

Montesperelli, P. 2014. Comunicare e interpretare. Introduzione all'ermeneutica per la ricerca sociale (To Communicate and to Interpret. Introduction to the Ermeneutica for the Social Research). Milano: Egea.

Moulaert, F., D. MacCallum, A. Mehmood, and A. Hamdouch. 2013. "General Introduction: The Return of Social Innovation as a Scientific Concept and a Social Practice." Pp. 1-8 in The International Handbook on Social Innovation: Collective Action, Social Learning and Transdisciplinary Research, edited by F. Moulaert, D. MacCallum, A. Mehmood, and A. Hamdouch. Cheltenham,
UK: E. Elgar Publishing.

Mulgan, G. and L. Pulford. 2010. "Study on Social Innovation." A paper prepared by the Social Innovation eXchange (SIX) and the Young Foundation for the Bureau of European Policy Advisors. Retrieved (https://youngfoundation.org/ wp-ontent/ploads/2012/10/Study-on-Social-Innovation-for-t he-Bureau-of-European-Policy-Advisors-March-2010.pdf).

Mulgan, G., S. Tucker, R. Ali, and B. Sanders. 2007. Social Innovation: What It Is, Why It Matters and How It Can Be Accelerated. London: The Basingstoke Press.

Peruzzi, G. 2011. Fondamenti di comunicazione sociale. Diritti, media, solidarietà (Fundamentals of Communication of Social Issues. Rights, Media, Solidarity). Roma: Carocci.

Peruzzi, G. and A. Volterrani. 2016. La comunicazione sociale. Manuale per le organizzazioni non profit (Communication of Social Issues. Handbook for Non-profit Organizations). Roma-Bari: Laterza.

Storey, D. 2012. Territory: The Claiming of Space. Edinburgh: Pearson Education.

Tramma, S. 2009. Pedagogia della comunità. Criticità e prospettive educative (Pedagogy of the Community. Critical Issue and Educational Perspectives). Milano: Franco Angeli.

Tremblay, D. G. and M. Alberio. 2013. "Temps professionnels, temps prescrits, temporalités sociales" (Professional Time, Prescribed Time, Social Temporalities). SociologieS (on line). Retrieved January 2, 2017 (http://sociologies.revues. org/4433).

Van Dyck, B. and P. Van den Broeck. 2013. "Social Innovation: A Territorial Process." Pp. 31-42 in The International Handbook on Social Innovation: Collective Action, Social Learning and Transdisciplinary Research, edited by F. Moulaert, D. MacCallum, A. Mehmood, and A. Hamdouch. Cheltenham, UK: E. Elgar Publishing.

\section{Bios}

Gaia Peruzzi, Ph.D., associate professor of Sociology of Cultural and Communicative Processes at the Department of Communication and Social Research of the University of Rome "La Sapienza", Italy; research fields: communication of social issues, cultural politics for the Third Sector, media and migration, multicultural and gender identities.

Raffaele Lombardi, Ph.D., research fellow of Sociology of Cultural and Communicative Processes at the Department of Communication and Social Research of the University of Rome "La Sapienza", Italy; research fields: cultural process, corporate communication and education for the Third Sector. 